\title{
(idis)

\section{PENGARUH MANAJEMEN PENGETAHUAN DAN PENGALAMAN KERJA TERHADAP KINERJA PEGAWAI}

\author{
Rahma Oktafiana Rani, Syahrum Agung dan Muhamad Aziz Firdaus \\ Fakultas Ekonomi dan Bisnis Universitas Ibn Khaldun Bogor, Indonesia \\ Rahmaoktafiana@gmail.com,Syahrumagung.17@gmail.com, azisfirdaus@uika- \\ bogor.ac.id
}

\begin{abstract}
Kejaksaan is a government institution that carries out state power in the field of prosecution whose provisions are subject to Article 30 of Law Number 16 Year 2004 concerning kejaksaan republik indonesia, which is one of the main objectives of law enforcement in a modern, integrity, professional and accountable manner. based on justice and truth. This study aims to determine the Effect of Knowledge Man-agement and Work Experience on Employee Performance Kejaksaan Negeri Kabupaten Bogor. The method used by this researcher is a quantitative method using primary data in the form of observations and questionnaires. Then the sample used in this study was 68 employees. Based on the results of this study indicate that Knowledge Management and Work Experience have a significant effect on employee performance. From these results it can be concluded that Knowledge Management and Work Experience will improve employee performance on Kejaksaan Negeri Kabupaten Bogor.
\end{abstract}

Keywords: Knowledge Management, Work Experience, Performance.

\begin{abstract}
Abstrak
Kejaksaan adalah sebagai lembaga pemerintahan yang melaksanakan kekuasaan negara di bidang penuntutan yang ketentuannya tunduk pada Pasal 30 Undang-Undang Nomor 16 Tahun 2004 tentang kejaksaan republik indonesia, yang salah satu tujuan utamanya adalah melakukan pengeakan hukum secara modern, berintegritas, profesional dan akuntabel, yang berlandaskan keadilan dan kebenaran. Penelitian ini bertujuan untuk mengetahui Pengaruh Manajemen Pengetahuan dan Pengalaman Kerja Terhadap Kinerja Pegawai Kejaksaan Negeri Kabupaten Bogor. Adapun Metode yang digunakan peneliti ini adalah metode kuantitatif dengan menggunakan data primer berupa observasi dan kuesioner. Lalu sampel yang digunakan dalam penelitian ini sebanyak 68 pegawai.

Berdasarkan hasil penelitian ini menunjukan bahwa Manajemen Pengetahuan dan Pengalaman Kerja sangat berpengaruh signifikan terhadap kinerja pegawai. Dari hasil tersebut bisa ditarik kesimpulan bahwa Manajemen Pengetahuan dan Pengalaman Kerja akan meningkatkan kinerja pegawai pada Kejaksaan Negeri Kabupaten Bogor.
\end{abstract}

Kata Kunci : Manajemen Pengetahuan, Pengalaman Kerja, Kinerja. 


\section{Pendahuluan}

\section{Latar Belakang Penelitian}

Setiap instansi dalam melakukan aktivitasnya memiliki tujuan yang harus capai. Sumber daya manusia menjadi umpan bagi suatu instansi untuk tetap dapat bertahan, sumber daya manusia merupakan peran utama dalam setiap kegiatan instansi. Walaupun banyaknya sarana dan prasarana serta sumber daya, tanpa dukungan sumber daya manusia kegiatan instansi tidak akan berjalan dengan baik.

Keberhasilan mencapai tujuan instansi didukung sepenuhnya dari perilaku dan kinerja pegawai. Kinerja pegawai merupakan hasil atau prestasi kerja pegawai yang dinilai dari segi kualitas maupun kuantitas berdasarkan standar kerja yang ditentukan oleh pihak perusahaan. Kinerja yang baik adalah kinerja yang optimal, yaitu kinerja yang sesuai standar perusahaan dan mendukung tercapainya tujuan instansi. Instansi yang baik adalah instansi yang berusaha meningkatkan kemampuan sumber daya manu-sianya, karena hal tersebut merupakan faktor kunci untuk meningkatkan kinerja pegawai juga untuk mencapai visi, misi, dan tujuan instansi

Melalui manajemen pengetahuan yang dimiliki seorang pegawai tetap tinggal dan menjadi aset instansi sekali pun secara fisik mereka telah meninggalkan instansi. Melalui manajemen pengetahuan pula organisasi dapat belajar dengan cepat sehingga adaptif terhadap peru-bahan yang terjadi, meningkatkan egalitas or-ganisasi.

Manajemen pengetahuan merupakan aktifitas merencanakan, mengumpulkan dan mengorganisir, memimpin dan mengendalikan data dan informasi yang telah dimiliki oleh sebuah instansi yang kemudian digabungkan dengan berbagai pemikiran dan analisa dari berbagai macam sumber yang kompeten.

Kesuksesan dan kinerja instansi bisa dilihat dari kinerja yang telah dicapai oleh pegawainya, oleh sebab itu instansi menuntut agar para pegawainya mampu menampilkan kinerja yang optimal karena baik buruknya kinerja yang dicapai 4 oleh pegawai akan berpengaruh pada kinerja dan keberhasilan instansi secara keseluruhan.

Selain latar belakang pendidikan pegawai dan manajemen pengetahuan,kinerja pegawai di pengaruhi oleh masa kerja atau pengalaman kerja pegawai juga berpengaruh terhadap kinerja. Masa kerja dan pengalaman kerja dalam pengatahuan dapat mempengaruhi kuliatas kinerja pegawai. Kinerja pegawai belum memiliki masa kerja atau pengalaman kerja yang cukup banyak.

Pengalaman kerja dan pengetahuan kerja mencerminkan tingkat penguasaan pengetahuan dan keterampilan yang dimiliki seorang pegawai dalam bekerja yang dapat diukur dari masa kerja dan jenis pekerjaan yang pernah di kerjakan pegawai.

Pengalaman merupakan suatu proses pembelajaran dan pertambahan perkembangan potensi bertingkah laku baik dari pendidikan formal maupun nonformal atau bisa diartikan sebagai suatu proses yang membawa seseorang kepada suatu pola tingkah laku yang lebih tinggi.

Pengalaman. Kerja adalah ukuran tentang lama waktu atau masa kerja yang telah ditempuh seseorang dapat memahani tugas-tugas suatu pekerjaan dan telah melaksanakan tugas dengan baik". Sumber daya manusia merupakan tokoh sentral 
dalam organisasi maupun instansi. Agar aktivitas manajemen berjalan dengan baik, perusahaan harus memiliki instansi yang berpengetahuan dan berketerampilan tinggi serta usaha untuk mengelola perusahaan seoptimal mungkin sehingga keberhasilan perusahaan tercapai.

\section{Tujuan Penelitian}

1. Untuk mengetahui pengaruh antara mana-jemen pengetahuan terhadap kinerja pegawai Ke-jaksaan Negeri Kabupaten Bogor.

2. Untuk mengetahui pengaruh antara pengalaman kerja terhadap kinerja pegawai Kejaksaan Negeri Kabupaten Bogor.

3. Untuk mengetahui pengaruh kinerja kinerja pegawai Kejaksaan Negeri Kabupaten Bogor.

4. Untuk mengetahui pengaruh antara mana-jemen pengetahuan dan pengalaman kerja terhadap kinerja pegawai Kejaksaan Negeri Kabupaten Bogor.

\section{Metode Penelitian}

Jenis penelitian yang digunakan pada penelitian

ini adalah penelitian penjelasan (explanatory re-search). Pada penelitian dilakukan pengujian hipotesis dalam menjelaskan pengaruh manajemen pengetahuan dan pengalaman kerja terhadap kinerja pegawai kejaksaan negeri kabupaten bogor.

Pendekatan yang digunakan pada penelitian ini adalah pendekatan kuantitatif. Metode pengumpulan data dengan menggunakan kuesioner dengan jumlah 68 responden.
Objek penelitian yang dilakukan saat ini adalah seluruh pegawai pada Kejaksaan Negeri Kabupaten Bogor sebanyak 83 orang. Prosedur penarikan sampel yang digunakan dalam penelitian ini adalah sebagai berikut :

\section{Populasi}

Populasi dalam penelitian ini adalah seluruh karyawan pada Kejaksaan Negeri Kabupaten Bogor yaitu sebanyak 83 orang.

\section{Sampel}

Sampel adalah bagian dari populasi yang di ambil dari sumber data dan dapat mewakili seluruh populasi. Adapun teknik penarikan sampel dalam penelitian ini adalah menggunakan sampel random sampling. Menurut Sugiyono (2017, hlm. 67) mengemukakan bahwa "sampel random sampling adalah pengambilan anggota sampel dari populasi dilakukan secara acak tanpa memperhatikan strata yang ada dalam populasi”.

Teknik pengumpulan data dalam penelitian ini menggunakan angket atau kuesioner. Kuesioner merupakaan teknik pengumpulan data yang dilakukan dengan cara memberikan pernyataan tertulis kepada responden untuk dijawab. Kuesioner merupakan teknik pengumpulan data yang efisien, bila peneliti tahu dengan pasti variable yang akan diukur dan tahu apa yang bisa diharapkan dari respondern. Selain itu, kuesioner juga cocok digunakan bila jumlah responden cukup besar dan tersebar. Kuesioner dapat berupa pertanyaan atau pernyataan terbuka atau tertutup, dapat diberikan kepada responden secara langsung.

Sumber : Sugiyono (2012, hlm. 80)

\section{Teknik Pengumpulan Data}

1. Data primer (primary data) 
Data primer adalah data yang dikumpulkan sendiri oleh perorangan/suatu organisasi langsung melalui objeknya.

2. Data sekunder (secondary data)

Data sekunder adalah data yang diperoleh dalam bentuk yang sudah jadi berupa publikasi. Data sudah dikumpulkan oleh pihak/instansi lain.

\section{Teknik Analisis Data}

Pengolahan data yang dilakukan dalam penelitian ini menggunakan aplikasi SPSS (Statistical Package for Social Science) for windows. Aplikasi ini digunakan untuk melakukan analisis statistic seperti: uji instrument, uji asumsi klasik, uji regresi, analisis jalur antara dua variabel atau lebih. Berdasarkan tujuan dari penelitian ini, maka beberapa teknik analisa data yang akan digunakan dalam penelitian ini adalah sebagai berikut:

\section{Statistik Deskriptif}

Statistik deskriptif adalah statistik yang berfungsi untuk mendeskripsikan atau memberi gambaran terhadap obyek yang diteliti melalui data sampel atau populasi sebagaimana adanya, tanpa melakukan analisis dan membuat kesimpulan yang berlaku untuk umum Sugiyono (2017, hlm. 29).

\section{Uji Validitas}

Menurut Ghozali (2013, hlm. 53), uji validitas yang digunakan pada penelitian ini digunakan untuk uji moment product correlation atau dikenal dengan nama pearson correlation. Uji signifikan dengan dilakukan dengan membandingkan nilai $r$ hitung dengan nilai $r$ table, untuk degree of freedom (df) $=n-2$ dalam hal ini "n" adalah jumlah sampel dengan alpha = 0,05 .
3. Uji Reliabilitas

Menurut (Ghozali, 2013, hlm. 47) reliabilitas merupakan alat untuk mengukur suatu kuesioner yang merupakan indikator dari variabel atau konstruk dan suatu kuesioner dapat dinyatakan reliabel atau handal jika jawaban seseorang terhadap pernyataan adalah stabil dari waktu ke waktu.

4. Uji Normalitas

Uji normalitas digunakan untuk menguji apakah dalam model regresi, terdapat distribusi normal antara variabel terikat dan variabel bebas. Apabila distribusi data normal atau mendekati normal, berarti model regresi adalah baik.

5. Uji Analisis Jalur

Untuk menguji pengaruh variabel intervening digunakan metode analisis jalur (Path Analysis). Analisis jalur merupakan perluasan dari analisis regresi linear berganda atau analisis jalur adalah penggunaan analisis regresi untuk menaksir hubungan kausalitas antar variabel (model casual) yang telah ditetapkan sebelumnya berdasarkan teori.

\section{Hasil dan Pembahasan \\ Uji Validitas}

Hasil uji validitas dalam penelitian ini dihitung dari setiap variabel yaitu manajemen pengetahuan, pengalaman kerja, kinerja pegawai. Hasil dari uji validitas ini dapat dilihat dengan membandingkan hasil antara $r$ hitung dengan $r$ tabel. $r$ tabel dalam penelitian ini adalah $(\mathrm{df}=\mathrm{n}-2,68-2=66)$ sebesar 0,238. Hasil uji validitas dalam penelitian ini adalah sebagai berikut: 
Tabel 1

Hasil Uji Validitas terhadap Manajemen Pengetahuan (X1)

Item-Total Statistics

\begin{tabular}{ccccc}
\hline & Scale Mean if Item Deleted & $\begin{array}{c}\text { Scale Variance if Item } \\
\text { Deleted }\end{array}$ & $\begin{array}{c}\text { Corrected Item-Total } \\
\text { Correlation }\end{array}$ & $\begin{array}{c}\text { Cronbach's Alpha if Item } \\
\text { Deleted }\end{array}$ \\
\hline X1.1 & 44,65 & 59,486 &, 729 &, 917 \\
X1.2 & 44,51 & 62,015 &, 678 &, 919 \\
X1.3 & 44,62 & 60,180 &, 785 &, 915 \\
X1.4 & 44,57 & 61,711 &, 921 \\
X1.5 & 44,74 & 60,526 &, 642 &, 917 \\
X1.6 & 44,68 & 62,730 &, 734 &, 919 \\
X1.7 & 44,66 & 61,451 &, 699 &, 918 \\
X1.8 & 44,65 & 62,441 &, 912 &, 920 \\
X1.9 & 44,60 & 59,198 &, 659 &, 914 \\
X1.10 & 44,56 & 61,922 &, 806 &, 923 \\
X1.11 & 44,63 & 57,609 &, 601 &, 915 \\
X1.12 & 44,25 & 67,653 &, 780 &, 930 \\
\hline
\end{tabular}

Sumber: Kuesioner (diolah, 2019)

Tabel 2

Hasil Uji Validitas terhadap Pengalaman Kerj (X2)

Item-Total Statistics

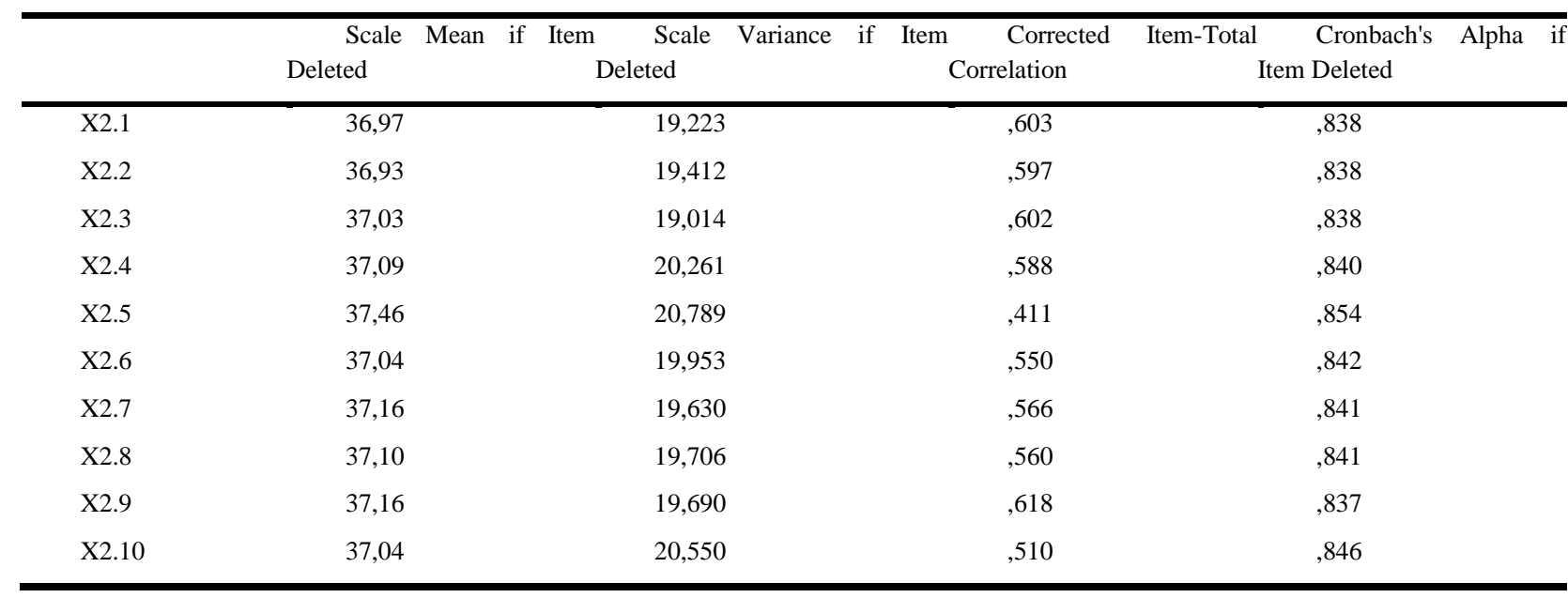

Sumber: Kuesioner (diolah, 2019)

Tabel 3

Hasil Uji Validitas terhadap Kinerja

Item-Total Statistics

\begin{tabular}{cccccc}
\hline \multicolumn{2}{c}{$\begin{array}{l}\text { Scale } \\
\text { Deleted }\end{array}$} & $\begin{array}{c}\text { Corrected } \\
\text { Sean }\end{array}$ & $\begin{array}{c}\text { If } \begin{array}{c}\text { Item-TotalCronbach's } \\
\text { Deleted }\end{array} \\
\text { Alpha }\end{array}$ & if \\
\hline Y1 & 35,57 & 54,069 &, 756 &, 939 \\
Y2 & 35,49 & 56,104 &, 761 &, 938 \\
Y3 & 35,65 & 55,754 &, 795 &, 937 \\
Y4 & 35,43 & 54,039 &, 734 &, 940 \\
Y5 & 35,71 & 54,569 &, 731 &, 940 \\
Y6 & 35,63 & 55,520 &, 803 &, 937 \\
Y7 & 35,66 & 54,973 &, 775 &, 938 \\
Y8 & 35,24 & 54,123 &, 819 &, 935 \\
Y9 & 35,66 & 54,436 &, 816 &, 936 \\
Y10 & 35,34 & 55,421 &, 712 &, 940 \\
\hline
\end{tabular}




\section{Uji Reliabilitas}

Kuesioner dikatan reliabel jika jawaban responden terhadap pertanyaan konsisten dan stabil. Pengujian reliabilitas dalam penelitian ini adalah menggunakan Cronbach Alpha. Hasil pengujian reliabilitas pada penelitian ini untuk variabel pengaruh manajemen pengetahuan dan pengalaman kerja yang terhadap kinerja dalam bekerja serta hasil kerja dari pegawai tersebut tersaji sebagai berikut:

\section{Tabel 4}

\section{Uji Reliabilitas terhadap Manajemen Pengetahuan (X1)}

Reliability Statistics

\begin{tabular}{ll}
\hline Cronbach's Alpha & N of Items \\
\hline, 925 & 12 \\
\hline
\end{tabular}

Sumber: Kuesioner (diolah, 2019)

Tabel 5

Uji Reliabilitas terhadap Pengalaman Kerja (X2)

\begin{tabular}{|c|c|c|c|c|c|}
\hline \multicolumn{6}{|l|}{ Model } \\
\hline & & $\mathrm{R}$ & R Square & Adjusted R Square & Std. Error of the Estimate \\
\hline dimension0 & 1 &, $776^{\mathrm{a}}$ & ,608 &, 595 & 1,855 \\
\hline
\end{tabular}

a. Predictors: (Constant), Manajemen Pengetahuan

Sumber: Kuesioner (diolah, 2019)

Disimpulkan bahwa semua variabel dalam penelitian ini memiliki koefisien cronbach's alpha diatas 0,60, sehingga dapat dinyatakan semua konsep pengukuran masing-masing variabel dari masing-masing kuesioner adalah reliabel. realiabilitas dilakukan secara bersama-sama terhadap seluruh pertanyaan dan jika nilai alpha > 0,60 maka disebut reliable.

\begin{abstract}
Analisis Jalur Headings
Dalam uji analisis jalur, ada dua bentuk pengujian yang dilakukan secara langsung dan tidak langsung yaitu model 1 adalah pengujian antara manajemen pengetahuan dan pengalaman kerja kepada kinerja. Kemudian model 2 adalah pengujian variabel manajemen pengetahuan, pengalaman kerja serta kinerja.
\end{abstract}

1. Analisis Hubungan antara Manajemen Pengetahuan (X1) dan Kinerja Pegawai(Y)

Hasil perhitungan, $\mathrm{R}=0,776$ terletak pada interval $(0,60-0,799)$, berdasarkan Tabel 4.20 hal ini menunjukkan bahwa hubungan antara variabel X1 (persepsi terhadap Manjemen Pengetahuan) dan Y (persepsi terhadap Kinerja Pegawai) adalah
Kuat dan positif. Berarti apabila $\mathrm{X} 1$ naik maka Y juga naik. 
2. Analisis Hubungan antara Pengalaman Kerja dan Kinerja Pegawai(Y)

Tabel 6

Model Summary

Model

R R Square Adjusted R Square Estimate

\begin{tabular}{rllll}
\hline $\begin{array}{c}\text { dimensi } \\
\text { on0 }\end{array}$ &, $366^{\mathrm{a}}$ &, 134 &, 121 & 2,098 \\
\hline
\end{tabular}

a. Predictors: (Constant), Pengalaman Kerja

Hasil perhitungan diatas, $\mathrm{R}=0,366$ variabel $\mathrm{X} 2$ (persepsi terhadap Pengalaman terletak pada interval $(0,20-3,99), \quad$ Kerja) dan $\mathrm{Y}$ (persepsi terhadap Kinerja berdasarkan Tabel 4.22 hal ini Pegawai) adalah sangat kuat dan positif. menunjukkan bahwa hubungan antara Berarti apabila X2 naik maka $Y$ juga naik.

3. Analisis Hubungan antara Manajemen Pengetahuan (X1), Pengalaman Kerja (X2) dan Kinerja Pegawai (Y)

Tabel 7

Model Summary

Model

Std. Error of the

R R Square Adjusted R Square Estimate

\begin{tabular}{ccccc}
\hline $\begin{array}{c}\text { dimen } 1 \\
\text { sion0 }\end{array}$ &, $777^{\mathrm{a}}$ &, 604 &, 591 & 1,865 \\
\hline
\end{tabular}

a. Predictors: (Constant), Pengalaman Kerja, Manajemen Pengetahuan

Sumber: Kuesioner (diolah, 2019)

Hasil perhitungan diatas, $\mathrm{R}=0,777$ terletak pada interval $(0,60-0,799)$,

1. Pengaruh Manajemen Pengetahuan terhadap Kinerja Pegawai pada berdasarkan Tabel 4.24 hal ini menunjukkan bahwa hubungan antara variabel X1 (persepsi terhadap Manajemen Pengetahuan) dan variabel X2 (persepsi terhadap Pengalaman Kerja) secara bersama-sama terhadap $\mathrm{Y}$ (persepsi terhadap Kinerja Pegawai) adalah kuat dan positif. Berarti secara bersama-sama kenaikan X1 dan $\mathrm{X} 2$ akan menyebabkan kenaikan Y.

Kejaksaan Negeri Kabupaten Bogor menurut analisis inferentif menunjukan hasil hubungan Manajemen Pengetahuan dengan kinerja pegawai Kejaksaan Negeri Kabaupaten Bogor, yaitu nilai $\mathrm{r}=0,776$ terletak pada interval $(0,60-0,799)$. Pada tabel 4.20 dapat dilihat hasil koefisien determinasi sebesar 0,608 atau (60 \%) memberikan arti bahwa besarnya pengaruh Manajemen Pengetahuan terhadap Kinerja sebesar $60 \%$, sedangkan sisanya $40 \%$ dipengaruhi oleh faktor- 
faktor lain yang tidak dimasukkan dalam penelitian ini. Hasil analisis regresi $\mathrm{Y}=2,456+0,796 \mathrm{X} 1$ dan uji thitung $=9,981>\mathrm{t}$ tabel $=1,996$, maka Ho ditolak (Ha diterima), berarti terdapat pengaruh yang signifikan antara Manajemen Pengetahuan terhadap Kinerja.

2. Pengaruh Pengalaman Kerja terhadap Kinerja Pegawai pada Kejaksaan Negeri Kabupaten Bogor menurut analisis inferentif menunjukan hasil Pengalaman Kerja dengan Kinerja pegawain pada Kejaksaan Negeri Kabaupaten Bogor menunjukan nilai $r$ $=0,366$ terletak pada interval $(0,20-$ 0,399). Berdasarkan Tabel 4.22, hal ini menunjukkan bahwa hubungan antara variabel X2 (Pengalaman Kerja) dan Y (Kinerja) adalah Rendah dan positif. Berarti apabila X2 naik maka Y juga naik. Hasil koefisien determinasi sebesar 0,134 atau (13\%) memberikan arti bahwa besarnya pengaruh Pengalaman Kerja terhadap Kinerja sebesar $13 \%$, sedangkan sisanya $87 \%$ dipengaruhi oleh faktor-faktor lain yang tidak dimasukkan dalam penelitian ini. Hasil analisis regresi $\mathrm{Y}=30,337+$ 0,299 X2. Dengan uji Hipotesis parsial yang menunjukan $\mathrm{t}$ hitung $=3,195>\mathrm{t}$ tabel $=1,996$, maka Ho ditolak $(\mathrm{Ha}$ diterima), berarti Terdapat pengaruh yang signifikan antara Pengalaman Kerja terhadap Kinerja.

3. Pengaruh Manajemen Pengetahuan dan Pengalaman Kerja terhadap Kinerja Pegawai pada Kejaksaan Negeri Kabupaten Bogor. Hasil koefisien determinasi yang disesuaikan sebesar 0,604 atau $(60,4 \%)$, memberikan arti bahwa besarnya pengaruh Manajemen
Pengetahuan dan Pengalaman Kerja secara bersama-sama terhadap Kinerja sebesar 60,4\% sedangkan sisanya $39,6 \%$ dipengaruhi oleh faktor-faktor lain yang tidak dimasukan dalam penelitian ini. Hasil analisis regresi $\mathrm{Y}=$ $4,172+0,804 \mathrm{X} 1-0,49 \mathrm{X} 2$, uji hipotesis dengan menggunakan $F$ hitung $=49,484>\mathrm{F}$ tabel $=3,14$ maka Ho ditolak (Ha diterima), berarti Terdapat pengaruh yang signifikan antara Manajemen Pengetahuan dan Pengalaman Kerja secara bersama-sama terhadap Kinerja.

\section{Kesimpulan dan Saran}

\section{Kesimpulan}

1. Manajemen Pengetahuan dengan kinerja pada pegawai Kejaksaan Negeri Kabaupaten Bogor, yaitu nilai $r=0,776$ terletak pada interval $(0,60-0,799)$. Pada tabel 4.20, hal ini menunjukkan bahwa hubungan anatara variabel X1 (Manajemen Pengetahuan) dan Y (Kinerja) adalah Kuat dan positif. Berarti apabila X1 naik maka Y juga naik, dilihat hasil koefisien determinasi dapat dilihat hasil koefisien determinasi sebesar 0,608 atau (60\%) memberikan arti bahwa besarnya pengaruh Manajemen Pengetahuan terhadap Kinerja sebesar $60 \%$, sedangkan sisanya $40 \%$ dipengaruhi oleh faktorfaktor lain yang tidak dimasukkan dalam penelitian ini. Hasil analisis regresi $\mathrm{Y}=$ $2,456+0,796 \mathrm{X} 1$ dan uji thitung $=9,981$ $>\mathrm{t}$ tabel $=1,996$, maka Ho ditolak $(\mathrm{Ha}$ diterima), berarti terdapat pengaruh yang signifikan antara Manajemen Pengetahuan terhadap Kinerja. 
2. Pengalaman Kerja dengan Kinerja pegawain pada Kejaksaan Negeri Kabaupaten Bogor menunjukan nilai $r=$ 0,366 terletak pada interval $(0,20$ 0,399). Berdasarkan Tabel 4.22, hal ini menunjukkan bahwa hubungan antara variabel X2 (Pengalaman Kerja) dan Y (Kinerja) adalah Rendah dan positif. Berarti apabila X2 naik maka $\mathrm{Y}$ juga naik. Hasil koefisien determinasi sebesar 0,134 atau (13\%) memberikan arti bahwa besarnya pengaruh Pengalaman Kerja terhadap Kinerja sebesar 13\%, sedangkan sisanya $87 \%$ dipengaruhi oleh faktor-faktor lain yang tidak dimasukkan dalam penelitian ini. Hasil analisis regresi $\mathrm{Y}=30,337+0,299 \mathrm{X} 2$. Dengan uji Hipotesis parsial yang menunjukan $\mathrm{t}$ hitung $=3,195>\mathrm{t}$ tabel $=1,996$, maka Ho ditolak (Ha diterima), berarti Terdapat pengaruh yang signifikan antara Pengalaman Kerja terhadap Kinerja.

3. Manajemen Pengetahuan dan pengalaman kerja secara bersama-sama terhadap kinerja pada pegawai Pada pada Kejaksaan Negeri Kabaupaten Bogor menunjukan nilai $r=0,777$ terletak pada interval $(0,60-0,799)$. Berdasarkan Tabel 4.24, hal ini menunjukkan bahwa hubungan antara variabel X1 (Manajemen Pengetahuan) dan variabel X2 (Pengalaman Kerja) secara bersama-sama terhadap $Y$ (Kinerja) adalah Sangat Kuat dan positif. Berarti secara bersama-sama kenaikan $\mathrm{X} 1$ dan $\mathrm{X} 2$ akan menyebabkan kenaikan Y. Hasil koefisien determinasi yang disesuaikan sebesar 0,604 atau $(60,4 \%)$, mem-berikan arti bahwa besarnya pengaruh Manajemen Pengetahuan dan Pengalaman Kerja secara bersama-sama terhadap Kinerja sebesar 60,4\% sedangkan sisanya 39,6\% dipengaruhi oleh faktor-faktor lain yang tidak dimasukan dalam penelitian ini. Hasil analisis regresi $\mathrm{Y}=4,172+0,804 \mathrm{X} 1$ 0,49 X2, uji hipotesis dengan menggunakan $\mathrm{F}$ hitung $=49,484>\mathrm{F}$ tabel $=3,14$ maka Ho ditolak $(\mathrm{Ha}$ diterima), berarti Terdapat pengaruh yang signifikan antara Manajemen Pengetahuan dan Pengalaman Kerja secara bersama-sama terhadap Kinerja.

\section{Saran}

1. Pengaruh pengalaman kerja dapat ditingkatkan kembali dengan tindakan yang dapat dilakukan antara lain terlibatlah dalam banyak tugas, tanya kan apabila ada hal yang kurang jelas, tanyakan masukan tentang informasi yang berguna untuk meningkatan prospek pengalaman kerja.

2. Pengaruh pengalaman kerja dapat ditingkatkan melalui karakteristik dari lama bekerja seorang pegawai, faktor lama kerja yang berpengaruh terhadap hasil kerja pada saat penilitian dirasakan memang cukup kurang karan rata-rata untuk lama kerja $\geq 6$ tahun sebanyak 19 orang di kejaksaan negeri kabupaten bogor data tersebut sesuai dengan tabel 4.4.

3. Dalam penelitian ini, peneliti menyadarai bahwa masih banyak kekurangan yang peneliti miliki karena banyaknya keterbatasan. Diharapkan untuk penelitian selanjutnya dapat menggali lebih banyak informasi terkait dengan variabel-variabel lain yang dapat 
mempengaruhi manajemen pengetahuan dan pengalaman kerja terhadap kinerja pegawai.

\section{Daftar Pustaka}

Hasibuan, M. (2006). Manajemen Sumber Daya Manusia (Revisi). Jakarta: Bumi Aksara.

-. Hasibuan, M. (2010). Manajemen Sumber Daya Manusia. Jakarta: Bumi Aksara.

Handoko, T. H. (2001). Manajemen Personalia dan Sumber Daya Manusia. Yogyakarta: BPFE Yogyakarta.

- Handoko, T. H. (2013). Manajemen Personalia dan Sumber Daya Manusia. Yogyakarta: BPFE Yogyakarta.

-. Handoko, T. H. (2009). Manajemen (Keduapuluh). Yogyakarta: BPFE Yogyakarta.

-. Handoko, T. H. (2012). Manajemen. Yogyakarta: BPFE Yogyakarta.

Ismail Nawawi, I. (2012). Manajemen Pengetahuan (Knowledge Management). Bogor.

Ranupandojo H \& Suad Husnan. (1984). Manajemen Personalia (III). Yogyakarta: BPFE Yogyakarta.

Dessler, G. (2000). Manajemen Sumber Daya Manusia (Terjemahan). Jakarta: PT. Prenhallindo.

Manulang, M. (1984). Management Personalia. Jakarta: Ghalia Indonesia.
-. Manulang, M. (2014). Dasar-Dasar Manajemen. Yogyakarta: Gadjah Mada University Press.

Gaol, C. J. (2014). Human Capital (Manajemen Sumber Daya Manusia) Konsep, Teori, dan Pengembangan dalam Konfeks Prganisasi Publik dan Bisnis. Jakarta: PT. Gramedia Widiasarana.

Prawirosentono, S. (1999). Kebijakan Kinerja Pegawai. Yogyakarta: BPFE Yogyakarta.

Mangkunegara, A. P. (2012). Manajemen Sumber Daya Manusia (Cetakan Keduabelas). Bandung: PT. Remaja Rosdakarya.

-. Mangkunegara, A. P. (2013). Manajemen Sumber Daya Manusia Perusahaan (Cetakan Keduabelas). Bandung: PT. Remaja Rosdakarya.

Sugiyono. (2005). Metode Penelitian Bisnis. Bandung: Alfabeta.

Ghozali, I. (2013). Aplikasi Analisis Multivariat dengan Program IBM SPSS 21.

Ashari, P. B. S. (2005). Analisis statistic dengan Microsoft exel dan SPSS. Yogyakarta.

Achmad Ruki, A. S. (2001). Sistem Manajemen Kinerja. Jakarta: Gramedia Pustaka Utama.

Arikunto. (2006). Prosedur Penelitian Suatu Pendekatan Praktek. Jakarta: PT. Rineka Cipta. 
Nur Falah, A. S., \& Prasetya, A. (2017).

Pengaruh Knowledge management terhadap kinerja karyawan dan kinerja perusahaan (Studi pada karyawan PT. Semen Indonesia Persero Tbk). Jurnal Administrasi Bisnis, 50(4), 192198-198. Diambil dari http://administrasibisnis.studentjo urnal.ub.ac.id/index.php/jab/articl e/view/2048 